\title{
LA DUALIDAD DE JURISDICCIONES EN LA CASUISTICA DE LOS CONTRATOS DE LA ADMINISTRACION
}

$351.712: 340.142$

por

Jaime Sánchez Isac

SUMARIO: I. PLANTEAMIENTO DE LA CUESTION.-II. LA SITUACION DESPUES DE LA LEY DE LA JURISDICCION CONTENCIOSO-ADMINISTRATIVA. - III. POSTURAS CONCRETAS DE LAS SALAS DE LO CONTENCIOSO-ADMINISTRATIVO DEL TRIBUNAL SUPREMO.-IV. LA POSTURA DE LA SALA PRIMERA DE LO CIVIL DEL TRIBUNAL SUPREMO.-V. CONCLUSIONES.

\section{PLANTEAMIENTO DE LA CUESTION}

Al encararnos con el enunciado de este trabajo debemos subrayar, inicialmente, el peso doctrinal de la cuestión y la multitud de posturas, matizadas, meditadas, existentes en nuestra literatura jurídico-pública.

Existen unas exactas palabras del Profesor García-TreviJano, perfectamente vigentes (1): «... cuando se trata de llevar a la práctica la teoría material del contrato administrativo y, lo que es aún más importante, se trata de especificar número, nombres y clases de ellos, se encuentra el jurista ante uno de los problemas graves y que se resuelven por una especie de cláusulas de estilo menta-

(1) «¿Existen contratos administrativos de depósito?», R. A. P., núm. 16, página 156. 
les, pero de poco rigor jurídico. Al tratar de hacer una clasificación de los contratos administrativos ya no se pone de acuerdo la doctrina, ni mucho menos la legislación y la jurisprudencia. Se llega a un relativismo jurídico actuable, caso por caso".

En el presente artículo soslayamos deliberadamente cualquier investigación bibliográfica de dimensión vertical, para ceñinnos a una llana exposición horizontal de algunos supuestos jurisdiccionales concretos, en orden a la cuestión, eminentemente práctica, de la naturaleza civil o administrativa de los contratos de la Administración (2).

El "relativismo jurídico» que ello comporta tal vez sea insatisfactorio en un terreno de pureza dogmática y de elevación doctrinal. No hay otro deseo, en estas notas, que acotar con una serie de resoluciones del Tribunal Supremo, el interrogante básico que nos queda planteado en nuestra praxis jurídica, la dualidad de jurisdicciones, en materia de contratos de la Administración. Ello es así. Podrá o no podrá gustar. Pero en el momento de descender al romance de nuestras sentencias, comprobamos que esta dualidad sigue siendo la realidad jurídica y creemos que esta objetividad de la cuestión justifica un esfuerzo más en el campo, ya muy trillado, del casuismo contractual.

\section{LA SITUACION DESPUES DE LA LEY DE LA JURISDICCION CONTENCIOSO-ADMINISTRATIVA}

La Ley de la Jurisdicción contencioso-administrativa de 27 de diciembre de 1956, en sus artículos 2 a) y 3 a) ha establecido los dos polos normativos de las respectivas competencias ordinaria $y$ especial, en los contratos de la Administración. Realmente existe una línea clara en los dos preceptos.

Por una parte, «no corresponderán a la jurisdicción contencioso-administrativa: a) Las cuestiones de índole civil o penal atribuidas a la jurisdicción ordinaria...», y, por otra, la jurisdicción contencioso-administrativa conocerá de: «a) Las cuestiones referentes al cumplimiento, inteligencia, resolución y efectos de los contratos, cualquiera que sea su naturaleza jurídica, celebrados por la Admi-

(2) Véase, sobre la cuestión, en los Indices de la $R$. A. P., 1950-1973, (Instituto de Estudios Políticos), el epigrafe «Contratos administrativos y contratos civiles", páginas 908 y sigs. 
nistración pública, cuando tuvieren por finalidad obras y servicios públicos de toda especie».

Parece, a grandes rasgos, que el artículo 3, a), haya verificado un proceso de ampliación del foco de la jurisdicción especial, al hablar, de modo absolutamente amplio, de «cualquiera que sea su naturaleza jurídica", términos generosos, sólo limitados por la teleología contractual, que ha de ser la obra y el servicio público (3).

En la práctica jurídica no es rara la excepción dilatoria de la incompetencia de jurisdicción, alegada en una litis planteada ante la jurisdicción ordinaria y el análisis de la cuestión a la luz de los artículos citados, que se conjugan en el silogismo judicial para concederla o denegarla y, en consecuencia, para sentar la definición concreta de la naturaleza civil o administrativa del contrato discutido $\mathrm{y}$, por tanto, del órgano judicial competente.

Paralelamente, l'embarras du choix puede aparecer dentro de un recurso contencioso-administrativo como causa de inadmisibilidad.

Esta doble vía nos ha inducido a efectuar un cotejo jurisprudencial de las Salas del Tribunal Supremo, previo al cual no será ocioso insistir en un dato básico: el valor primario de la jurisprudencia contencioso-administrativa (4).

(3) Los Profesores E. Garcfa de Enterrfa y T.-R. FERnández han hecho notar el problema que el artículo $4 .^{\circ}$ de la Ley de Contratos del Estado de 17 de marzo de 1973 ha suscitado en cuanto de la redacción y "de entenderse como una ampliación del ámbito tradicional del contrato administrativo habría que concluir que esta figura tendria extensión distinta en la esfera de la Administración del Estado ( $\mathrm{y}$ de sus entes institucionales), donde se aplicarían los conceptos del artículo $4 .^{\circ}$, L. C. E., y en la esfera de la Administración local, donde se aplicaría el criterio del artículo $3 .^{\circ}$, L. J. (por la remisión del artículo 12, R. C. C. L.)». Entendemos que la postura de dichos autores está perfectamente en la línea de este estudio: "Por ello sería vano intentar interpretar el artículo $4 .^{\circ}$, L. C. E., contra el artículo $3 .^{\circ}$, L. J., en cuanto a la delimitación del ámbito propio de los contratos administrativos a los efectos de definir su competencia jurisdiccional. Creemos que resulta aconsejable, para evitar los equivocos derivados de la desacertada redacción del primer precepto, atenerse exclusivamente al segundo y a su interpretación jurisdiccional tradicional'.

Con ello entendemos que podemos dar un rodeo al problema sustancial de la clasificación de los contratos a la luz de la última formulación en el régimen estatal, para consagrar nuestra atención a la evolución de la jurisprudencia, objeto de este artículo. (Véase, de los autores citados, Curso de Derecho administrativo, I, página 514).

(4) "Tan Tribunales son hoy, valga la expresión, los de lo contencioso-administrativo como los civiles o penales. La L. J. es muy clara a este respecto, tanto en la regulación del articulado como en la justificación contenida en la Exposición de Motivos. Pero también la jurisprudencia es consciente del papel que es. tán llamados a desempeñar los Tribunales de lo contencioso-administrativo en la actualidad». Profesor don Lorenzo MartfN-Retortillo, "Unidad de jurisdicción para la Administración pública», $R$. $A$. $P$., núm. 49, página 172. 
El problema, también en el campo cotidiano, es cómo llegar a una mayor vigencia de esta virtualidad jurídica. Sobre todo cuando, como en nuestro tema ocurre, esta jurisprudencia contenciosoadministrativa tiene características de aperturismo y adaptación a la tendencia pedida por la doctrina: la unidad de jurisdicción para la Administración.

En la diaria y obsesiva lucha por el Derecho deben reseguirse, entre la mása agobiante de las resoluciones, estas inclinaciones tendenciales a los objetivos ideales o que se predican como tales. La permeabilidad entre doctrina y jurisprudencia es altamente discutible (5), en nuestro Derecho nacional, pero ello no nos exime, incluso a nivel de investigación concreta y microscópica, como la que aquí hacemos, del deber de acentuar aquellas coyunturas en que la interpretación del Derecho positivo coincide con lo que la doctrina ha considerado como deseable en lo perfectible.

Hechas estas obvias reflexiones pasamos a verificar un estudio de la jurisprudencia del Tribunal Supremo, en ambas jurisdicciones, para concretar las alturas respectivas de sus sistemas de trabajo, como objeto de este artículo que querríamos sirviera para esbozar la localización cronológica de los datos esenciales de una cuestión eminentemente problemática en muchos sistemas administrativos europeos (6).

\section{POSTURAS CONCRETAS DE LAS SALAS DE LO CONTENCIOSO-ADMINISTRATIVO DEL TRIBUNAL SUPREMO}

En sentencia de 25 de septiembre de 1970 (Aranzadi 3.742) de la Sala $4 .^{a}$ se dice, citando a la de primera instancia, en la referencia del considerando $3 .^{\circ}$ :

"... los matices diferenciadores de ambas clases de contratos han sido concretados y perfilados por la magistral sentencia del Tribunal Supremo de 26 de junio de 1965 (Aranzadi 3.621), a cuyo tenor, "si bien no existe una línea divisoria para deslindar los campos de lo estrictamente civil y lo fundamentalmente administrativo, la doctrina y la juris-

(5) Juan Alfonso Santamaría Pastor, "¿Crisis definitiva de la reformatio in pejus?», R. A. P., núm. 72, página 129.

(6) Para un tratamiento resumido y ejemplar del tema nos remitimos al Curso de Derecho administrativo, de los Profesores GARCfA DE ENTERRfA y Tomás-Ramón FERNÁNDEZ, páginas 512 y sigs. 
prudencia han establecido normas para determinar la naturaleza jurídica del contrato administrativo, atendiendo preceptivamente a los elementos subjetivos, al carácter y posición con que actúan los mismos y si la relación contractual tiende directa e inmediatamente a la ejecución de una obra o a la prestación de un servicio público».

En el caso se calificó de administrativo el contrato de venta de un solar, segregado de bienes de propios de un Ayuntamiento, con la condición de construcción en determinado plazo y la cláusula reversional estereotipada en el artículo 97, 2, del Reglamento de Bienes de las Corporaciones locales.

En sentencia de 4 de mayo de 1968 de la Sala 4. (Aranzadi 3.963) se estudia el cambio de régimen, en la materia, consiguiente a la sucesión de leyes de la jurisdicción:

Considerando 2. : "El precepto contenido en el artículo $30^{\circ}$ de la Ley Jurisdiccional, en su. actual redacción de 27 de diciembre de 1956, viene a añadir un criterio de ampliación respecto al artículo $5 .^{\circ}$ de la Ley Jurisdiccional de la Ley de 22 de junio de 1894, textualmente conservado en el texto refundido de 8 de febrero de 1952 y también en su artículo $5 .^{\circ}$, puesto que en el artículo $3 .^{\circ}$ de la Ley Jurisdiccional hoy vigente, a más de suprimir el modo adverbial "sin embargo» que iniciaba la antigua fórmula legal, añade a la frase empleada en la legislación anterior, mediante la cual se atribuía a la jurisdicción «las cuestiones referentes al cumplimiento, inteligencia, rescisión y efectos de los contratos celebrados por la Administración central, provincial y municipal para otros servicios públicos de toda especie" (pues tal era la antigua fórmula), la expresión cualquiera que sea su naturaleza, interpolada a continuación de la palabra «contratos», con lo que, indudablemente, como sugieren los comentarios doctrinales y como ya apreció la sentencia del Tribunal Supremo de 23 de marzo de 1961 (Aranzadi 1.520 ), en el criterio tradicional respecto a los elementos que caracterizan el contrato administrativo son su objeto y finalidad orientados al interés general; concepto que viene a afirmarse «con el indudable propósito - dice la sentencia- de incluir en el área administrativa, de modo expreso, figuras contractuales atípicas o de dudosa tipificación, relacionadas directamente con la consecución del fin público; con lo que, ya en primer término, ha de enfocarse la aplicación de la norma en sentido menos restrictivo y como susceptible de abarcar más amplio sector que el rigurosamente adscrito a las obras públicas y a los servicios en sentido estricto, aun sin necesidad de aplicar respecto a estos conceptos el módulo de la finalidad de la actividad administrativa, como contrario al formulismo casuista; con lo que queda delimitado en el aspecto evolutivo y doctrinal la exégesis de la norma en'su nueva redacción con arreglo a su desarrollo histórico legal, ratificado por la Jurisprudencia; bien entendido que el actual Reglamento de Contratación de las Corporaciones locales de 9 de enero de 1953 mantiene 
en sus artículos 12 y 99, asi como en su texto toda la nueva doctrina del contrato administrativo».

En el caso, la cuestión de fondo fue un contrato de construcción de viviendas de renta limitada, actuando un Ayuntamiento como promotor, convocado mediante concurso-subasta previo, que fue calificado de administrativo.

El nervio de la sentencia es la afirmación de que, con la nueva Ley de la Jurisdicción, se ha verificado una ampliación del sector de contratos adscritos a la misma, espíritu contrapuesto, sin duda, a la doctrina de la Sala 1. ${ }^{a}$, como veremos.

En sentencia de 15 de junio de 1967 de la Sala 5. ${ }^{2}$ (Ar. 3.369) encontramos un estudio de las calificaciones jurídicas de la actividad administrativa y su correlación con la competencia judicial, en términos de gran generalidad, engarzándose en nuestro tema, en cuanto estudia el artículo $3 .^{\circ}$ de la Ley de la Jurisdicción:

CoNSIDERANDo $2 .^{\circ}$ de la sentencia apelada: "Es incuestionable en el campo del Ordenamiento jurídico-administrativo, reconociendo la personalidad única de la Administración, la posibilidad de que ésta actúe en relaciones jurídicas de diferente naturaleza y contenido, por lo que cabe distinguir... una actividad (sustancialmente) administrativa de Derecho público, una actividad (sustancialmente) administrativa de Derecho privado y una actividad (sustancial y jurídicamente) privada de la Administración pública, concepción a la que no es ajena la vigente Ley reguladora de la Jurisdicción contencioso-administrativa en sus artícu$\operatorname{los} 1 .^{\circ}, 2 .^{\circ}$ y $3 .^{\circ} \ldots »$.

Considerando $7 .^{\circ}:$ «... si, en principio, la redacción de su artículo $3 .^{\circ}$ puede ofrecer alguna duda al recurrente, al interpretar la frase "cualquiera que sea su naturaleza jurídica" es de recordar que se refiere dicha expresión no a la naturaleza jurídico-pública o privada, sino a la diferente tipología contractual que pueda producirse en el campo de las relaciones jurídico-públicas, pues dicho precepto hay que relacionarlo con el correcto criterio mantenido en su artículo $11^{\circ}$ que, con perfecta terminología - a diferencia de la empleada en el artículo $1 .^{\circ}$ de la Ley derogada de 22 de junio de 1894-, somete a esta jurisdicción los actos de la Administración pública sujetos al Derecho administrativo, corroborado todo ello por el artículo $2 .^{\circ}$ incluido en el capítulo primero de la Ley determinador de los límites de esta jurisdicción...».

Sin duda, la división de las actividades jurídicas de la Administración, que se verifica en la resolución judicial, puede ser materialmente defendible. Ahora bien, la interpretación de los tres pri- 
meros artículos, en términos generales, es altamente problemática. Sirva como testimonio de la complejidad de esta interpretación la versión que encontramos en la obra de J. L. GoNZÁlEz-BERENGUER URRUTIA, La contratación administrativa (7).

De las sentencias estudiadas se concluye que nuestras Salas de lo Contencioso del Tribunal Supremo mantienen una postura aperturista, interpretando la fórmula del artículo $3 .^{\circ}$, a), de la Ley de la Jurisdicción como fórmula omnicomprensiva que asigna a la competencia contenciosa incluso los contratos atípicos o de dudosa calificación.

La fórmula ostenta, efectivamente, la suficiente amplitud conceptual como para admitir una labor jurisprudencial dotada de dinamismo y elasticidad, aun contando con la resbaladiza naturaleza del tema (8).

(7) Municipalia, Madrid, 1966, página 41: «Como sagazmente ha demostrado Martín Retortillo, S., la estructura de la Ley de la Jurisdicción contenciosa, en sus tres primeros artículos, es la siguiente: el artículo $1 .^{\circ}$ declara sujetos a la jurisdicción todos los actos emanados de la Administración pública y que están sujetos al Derecho administrativo; el artículo 2. complementa al anterior, aludiendo a los actos que, aunque emanados de la Administración pública, no están sujetos al Derecho administrativo, y por ello no son materia de la jurisdicción; el artículo $3 .^{\circ}$, por último, se refiere a tres supuestos actos que, en todo caso, y a pesar de su naturaleza, posiblemente no administrativa, están sujetos a la jurisdicción contenciosa: los actos a los que una Ley especial se refiere expresamente, los problemas de responsabilidad civil y los contratos que tengan como finalidad obras o servicios públicos, cualquiera que sea la naturaleza de estos contratos. Martín Retortillo piensa, y con él toda la doctrina, que la Ley se está refiriendo con ello a contratos de la Admininstración, de carácter civil, cuya finalidad es la obra o el servicio público, y que tales contratos - no obstante ser civiles- están sometidos a la jurisdicción contenciosa. (En contra, Trujillo, Quintana y Bolea, sosteniendo que la Ley se refiere a los diversos objetos contractuales)».

El propio GONZÁLEZ-BERENGUER opina: "Ahora bien, ¿siempre y en todo caso el contrato que Ileva a cabo la Administración es contrato administrativo? ¿En ningún momento repugnará a la dialéctica interna del contrato la aparición de soluciones consagradoras de la desigualdad de las partes? Creemos aplicable aquí la tesis de García de Enterría en el sentido de que la utilización de figuras civiles por la Administración pública es una mera utilización instrumental, no dejando en ningún momento de ser Derecho administrativo las normas que efectúan la remisión al Derecho civil; es decir, en todo momento la Administración usa su propio Derecho, y este Derecho en ocasiones declara la aplicabilidad de las mismas normas civiles, de la misma manera que puede declarar la aplicabilidad de una técnica operativa cualquiera. Pues bien, en el mundo contractual creemos que sucede otro tanto, y que (aparte de cosechar la posibilidad de que existan contratos de la Administración cuya finalidad próxima o remota no sea la obra o el servicio público, con lo cual sostenemos que todos los contratos de la Administración deberían ser examinados por los Tribunales Contenciosos), cuando la Administración en sus contratos se acoge a normas de Derecho privado, lo hace de manera instrumental, y estas normas quedan inmersas dentro de un armazón contractual total de carácter jurídico-administrativo».

(8) Procede citar en la misma línea extensiva:

- Sentencia de 7 de abril de 1962, Sala 4. ${ }^{\circ}$, Aranzadi 1.974. Es administrativo el contrato suscrito entre la Comisaría de Abastecimientos y Transportes y una 
Dentro de esta visión absorbente de la jurisdicción especial destaca la sentencia de 16 de marzo de 1973 de la Sala 4. ${ }^{a}$ (Aranzadi 1.195), donde se declara administrativo el contrato de adjudicación y subsiguiente urbanización de dos parcelas del patrimonio de un Municipio, aunque se actuó mediante un servicio municipalizado, sin monopolio, debidamente aprobado por la superioridad.

sociedad que vendió a aquélla bidones vacíos usados como envases de aceite de soja. Considerando $3 .^{\circ}:$ «En el aspecto práctico ofrece escaso interés el extremo referente a la naturaleza del contrato concertado el 10 de junio de 1959 entre la Comisaría de Abastecimientos y Transportes, como vendedora, y C. y S. S. A., en calidad de compradora, sobre compra-venta de 50.000 bidones vacíos por el precio total de 125.000 dólares...; y aunque dichas circunstancias serían inoperantes en el supuesto de efectiva incompetencia, que como materia de orden público podría ser relevado de oficio por la Sala, es lo cierto que el apartado $a$ ) del artículo $3 .^{\circ}$ de la Ley de 27 de diciembre de 1956 atribuye al conocimiento de los Tribunales de lo Contencioso-administrativo las cuestiones referentes al cumplimiento, inteligencia, resolución y efectos de los contratos, cualquiera que sea su naturaleza juridica, celebrados por la Administración cuando tuvieren por finalidad obras y servicios públicos de toda especie, precepto interpretado por las sentencias de esta Sala de 15 de junio de 1959 y 2 y 25 de marzo de 1960 , en el sentido que la indiferencia en el tipo de las obligaciones concertadas sirve para encuadrar administrativamente todas aquellas que lo tengan intermedio o dudoso, siempre que intervenga un organismo oficial y persigan un fin público, cual aquí acontece al figurar como parte la Comisaría General de Abastecimientos y Transportes y tener como objeto la enajenación de envases vacios procedentes de la importación de artículos destinados al consumo para minorar con su importe el total de la operación, permitiendo fijar precios más bajos en el mercado nacional».

- Sentencia de 26 de junio de 1965, Sala 3.2, Aranzadi 3.621. Es administrativo el contrato de arrendamiento de almacenes concertado por una. Junta de Obras de Puerto con una entidad bancaria.

- Sentencia de 25 de noviembre de 1966, Sala 4. ${ }^{2}$, Aranzadi 5.702. Se considera administrativo el contrato existente entre la Comisaría General de Abastecimientos y Transportes y una sociedad anónima, sobre transporte de trigo, concertado entre Alicante y las Islas Canarias. "... precisa rechazar de plano la alegación de inadmisibilidad dicha, por no ser atendible la excepción de incompetencia propuesta, ante la evidencia de que la litis versa sobre las consecuencias de un contrato administrativo de servicio público, y es por ello, en la misma, de observar la indudable competencia que a esta jurisdicción otorga sobre el particular el apartado a) del artículo $30^{\circ}$.

- Sentencia de 9 de junio de 1967, Sala 4. ${ }^{2}$, Aranzadi 3.120. Contrato innominado o atípico. Se trata de la resolución de un contrato de venta de un solar, efectuada por un Ayuntamiento, a cambio de una obra de pavimentación de calles y edificación de viviendas. Se admitió tal resolución por incumplimiento. (Sentencia apelada: "Aun cuando el contrato, a tenor del pliego de condiciones que rigió la subasta y la escritura pública en que aquél se plasmó, se configuró como de compra-venta de una finca de bienes de propios..., tratándose de un contrato atipico o innominado... en el que, por el Ayuntamiento, existía una obligación de dar la transmisión de la propiedad de los terrenos innominados, y por los señores..., dos obligaciones de hacern).

- Sentencia de 23 de octubre de 1972, Sala 4.", Aranzadi 4.624. Contrato atípico administrativo de construcción de un camino vecinal y contraprestación de explotación de unos montes, propiedad de una Junta vecinal.

(Sentencia apelada: Aplica la doctrina de los actos separados: Considerando 2.०: «... surge aquí la cuestión de si el acto impugnado era susceptible o no de impugnación en la vía jurisdiccional, debido a su posible naturaleza de trámite, así como la concurrencia del acuerdo de la Excelentísima Diputación que lo autoriza, va- 


\section{De esta sentencia cabe destacar el texto concreto:}

«Por tratarse de actos los que aquí se impugnan que afectan a obras de urbanización y tratarse de un servicio municipalizado, cualquiera que sea el órgano que las ejecute o pretenda llevarlas a efecto es a esta Jurisdicción a la que corresponde conocer de todas las incidencias derivadas de tales actos administrativos, puesto que según el Reglamento de Servicios de las Corporaciones locales de 17 de junio de 1955, establece en casos como el presente que la dirección y administración de la Empresa constituida de tal modo habrá de asumirse por la Cor-

riando su contenido sustancialmente; pero la competencia de la jurisdicción para fiscalizar dicho acto de la Junta resulta evidente por aplicación de la doctrina de los "actos separados", según la cual existe la posibilidad de controlar toda actividad administrativa precontractual dirigida a la celebración de un contrato y sometida a las normas de Derecho administrativo, cuya fiscalización se ha venido manteniendo con reiteración por la jurisprudencia del Tribunal Supremo, pudiendo citarse, entre otras, las sentencias de su Sala 4. ${ }^{2}$ de 19 de enero de 1959 (Ar. 171), 17 de octubre de 1961 (Ar. 3.677) y 27 de diciembre de 1963 (Ar. 1.964, 32)".

- Sentencia de 13 de noviembre de 1972, Sala 4. ${ }^{\circ}$, Ar. 4.370. Venta de solares ccn cbligación de construir y cláusula reversional explícita.

Sentencia apelada: Considerando $20^{\circ}$ : «... aun reconociendo lo revuelto de la polémica, a veces hiperbólica, en torno a los criterios diferenciadores, en esta hipótesis concreta no ofrece duda alguna el carácter administrativo del mismo, porque si se acepta, como parece privar fundamental y actualizadamente en la doctrina y en la jurisprudencia, por el criterio del objeto y finalidad del contrato y de la específica competencia como sustrato y nervio de la diferenciación, aparece con nítida claridad que por medio de la relación jurídica contraída la Corporación municipal, lejos de perseguir la obtención del precio estipulado, como lo demuestra su alcance módico y reducido, pretendía cumplir finalidad pública dentro de su competencia singular, cual es la de urbanizar y edificar toda la zona del campo de útbol...".

- Sentencia de 21 de noviembre de 1972, Sala 4. ${ }^{2}$, Aranzadi 5.049. Venta de sclares en pública subasta, de propiedad municipal, para construcción de ciudad veraniega, con cláusula resolutoria de reversión en caso de inedificabilidad. Se ejercitó tal reversión en ampliación del pliego de condiciones adaptado al articulo 65,1 , del Reglamento de Contratación. La Sala de la Jurisdicción de la Audiencia Territorial confirmó el acuerdo municipal, y asimismo el Tribunal Supremo.

Considerando $4 .^{\circ}$ de la sentencia apelada, aceptado: «... dado el carácter administrativo del contrato de compra-venta de las parcelas litigiosas, concluido entre los recurrentes y la Corporación demandada, a través del procedimiento de adjudicación en subasta, que también se da en el Derecho privado, carácter aquel que no ha sido negado por las partes y que en todo caso le correspondería de conformidad con la doctrina sustentada por el Tribunal Supremo en sentencias como las de 26 de junio de 1965 (Ar. 3.621), 4 de mayo de 1968 (Ar. 3.963), 3 de marzo y 2 de diciembre de 1969 (Ar. 1.443, 5.596) y 25 de septiembre de 1970 (Ar. 3.742), la interpretación del artículo $6 .^{\circ}$ del pliego de condiciones, clave para la resolución de las cuestiones planteadas en este proceso, habrá de hacerse de acuerdo con lo en él estipulado, con lo establecido en los artículos 65 a 71 del Reglamento de Contratación y con las disposiciones del Código civil, especialmente las contenidas en su artículo 1.113».

Considerando del Tribunal Supremo: «La cuestión fundamental al objeto del presente litigio aparece resuelta en la sentencia objeto de apelación, ya que estriba en el carácter típicamente administrativo del contrato, en cuya materia es la finalidad del mismo quien revela la condición determinante, referida aquí a una materia urbanística, como es la creación de una ciudad veraniega, típica de la actividad y de la naturaleza de la Administración...». 
poración municipal respectiva, la cual se acomodará a lo dispuesto en la Ley de Régimen local de 24 de junio de 1955 y Reglamento de Organización, Funcionamiento y Régimen jurídico de los Ayuntamientos y Diputaciones provinciales de 17 de mayo de 1952, lo que también concuerda con el carácter y naturaleza de las peticiones que se formulan en la demanda y que, en general, se refieren, sin ninguna duda, a una serie de actos que, por su índole y finalidad y por los órganos de que proceden, son de la competencia de esta Jurisdicción, razones que, unitas a las que se contienen en la sentencia apelada, vienen a patentizar la improcedencia de esta causa de inadmisibilidad del presente recurso» (9).

Esta sentencia sienta la doctrina de que cualquier acto de un servicio municipalizado, en forma legal, es propio de la jurisdicción contenciosa, afirmación que, evidentemente, puede tener gran peso práctico en múltiples materias que se gestionan por tales servicios.

Creemos que no es posible dar más amplitud al artículo $3 .^{\circ}$, a), de la Ley de la Jurisdicción, en cuanto que, según el artículo 164 de la Ley de Régimen local, "los Municipios podrán explotar directamente servicios de naturaleza mercantil, industrial, extractiva, forestal o agrícola que sean de primera necesidad o utilidad pública...», mediante el régimen de municipalización.

Si continuamos la dialéctica del texto legal tendremos que convenir en que serán administrativos los contratos en materia de abastecimientos de agua, electricidad, gas, recogida y aprovechamiento de basuras, alcantarillado, lonjas, mercados, mataderos, cámaras frigoríficas, pompas fúnebres y los de autobuses, tranvías, trolebuses, ferrocarriles y demás medios de transporte, en cuanto que son objeto de posible municipalización con monopolio (artícu-

(9) Considerando 2.० de la sentencia apelada: «... basta con la lectura del artículo $3 .^{\circ}$ para rechazar tal tesis por errónea, puesto que... postulado entre otros extremos la nulidad como contrarios a derecho, de la adjudicación y subsiguiente contrato de urbanización de las dos parcelas del patrimonio del Ayuntamiento de A., que con la finalidad prevista en el artículo 138 de la Ley del Suelo, fueron desafectadas del Monte Pinar del Común o Pinar de Propios, contrato cuya naturaleza no queda desvirtuada por el hecho de que en lugar de ser el propio Ayuntamiento el que de forma directa la concertara, se verificara por la sociedad anónima municipal expresada, constituida con esta exclusiva finalidad, la de llevar a buen término y fin la urbanización deseada por el Ayuntamiento citado, sobre las dos mencionadas parcelas, cuya aportación constituyó e integró la totalidad del capital social, porque la vinculación de ésta a la Corporación local, su dependencia viene determinada por su propia naturaleza y causa de constitución..., y su subordinación...; por su objeto, es un servicio municipalizado, como de manera expresa se reconoce y declara en la escritura pública de constitución...; hechos todos estos que confirman la improcedencia de la causa de inadmisibilidad aducida. ya que si se trata de servicio municipalizado, cualquiera que sea el órgano que los ejecuta o pretenda llevar a efecto, esta Jurisdicción es la que ha de ccnocer de las incidencias derivadas a tales actos administrativos". 
lo 166 de la Ley de Régimen local). E idénticamente el servicio de suministro al por mayor de carnes, pescado, leches, frutas y verduras, mediante la adquisición en firme de estos artículos o su venta en comisión... (artículo 166, 2.).

Creemos que en los estrechos moldes de este artículo no caben las conclusiones que podrían plantearse frente a la naturaleza esencialmente mercantil, industrial, etc., de los servicios municipalizados, definida por la Ley, y la adscripción a la jurisdicción contencioso-administrativa de todos los contratos verificados por los mismos.

Queda el tema como el punto más avanzado, que conocemos, en la aplicación del precepto, totalmente actual y sugerente en grado sumo.

No olvidamos con ello nuestra condición de municipalista, que nos obliga a ver el Derecho desde el duro banco de nuestra labor diaria. Ello condiciona, para todos nosotros, indefectiblemente, la meditación de las grandes cuestiones del Derecho administrativo, que se sustancian y cristalizan, en nuestra óptica profesional, en concretísimas cuestiones. La necesidad de basar nuestro trabajo en los fundamentos generales del Derecho y en las tendencias imperantes en la jurisprudencia nacional, son argumentos importantes para anclar nuestra formación y nuestro estudio en sólidos fondos jurídicos. Pero no podemos desdeñar la consideración básica de que la función local se ciñe, usualmente, a problemas con coordenadas de Derecho positivo y jurisprudencia similar.

\section{LA POSTURA DE LA SALA PRIMERA DE LO CIVIL DEL TRIBUNAL SUPREMO}

Es interesante contrastar las clarísimas afirmaciones de extensión de la jurisdicción especial con las emanadas de la Sala 1. ${ }^{a}$, en la materia que estudiamos, ciertamente bien distinta.

En sentencia de 24 de junio de 1968 (Aranzadi 3.569) ha dicho, resolviendo excepción dilatoria:

«... como ha declarado esta Sala en su sentencia de 2 de febrero de 1942, en principio la materia de contratación forma parte del contenido propio del Derecho privado, quedando incluidas en la esfera de la jurisdicción ordinaria las contiendas judiciales que se susciten con motivo de la relación jurídico-contractual y, por excepción de la Ley, 
atribuye el conocimiento de esta relación jurídica a los Tribunales de lo Contencioso-administrativo en aquellos casos en que la Administración, como parte, actúa en el ejercicio del jus imperii, y por especial prerrogativa marca la norma a seguir, se ha de tener en cuenta que si surge pugna jurisdiccional habrá de ser resuelta con criterio extensivo en favor de los Tribunales del fuero ordinario, representativos de. la Jurisdicción común y atrayente, siempre que claramente no concurran los requisitos especificos que determinan, según ley, la competencia del Tribunal especial, procediendo por todo lo expuesto la estimación del recurso».

Es interesante esta doctrina de la Sala $1 .^{2}$, articulada, en la misma sentencia, en el juego de la doble resolución del más Alto Tribunal de la Nación, en cuanto sienta el criterio, de la jurisdicción ordinaria, de su carácter preferente si no concurre «claramente» el cuadro expresado por la Ley de 27 de diciembre de 1956.

En la misma línea, la sentencia de la propia Sala $1 .^{\mathrm{a}}$ de 3 de enero de 1962, donde se resuelve recurso de injusticia notoria y se califica de civil un contrato de arrendamiento de teatro-cine municipal, en base de tratarse de un bien no de un servicio municipal, a la luz de la litis. Es de destacar que existían cláusulas de reservas de derechos, para la Corporación, poco habituales en un arrendamiento y que el servicio se encontraba, al parecer, municipalizado (10).

El texto de la misma sentencia razona la postura del modo siguiente:

Considerando 2.0: "El examen del clausulado del contrato cuya calificación es la única cuestión discutida en este pleito, pone de manifiesto que el objeto de dicho contrato no es un servicio, sino uno de los bienes del patrimonio municipal, diciéndose expresamente en su cláusula primera que "es objeto de contrato el total del edificio del Teatro B., con sus depedencias e instalaciones", y en la segunda que los arrendatarios abonarán 50.000 pesetas, con lo cual aparecen determinadas las dos prestaciones recíprocas características del arrendamiento de cosas, sin que se desvirtúe el objeto del arrendamiento por el hecho de que se añada que esta renta se abonará por el disfrute $y$ explotación del servicio municipalizado del Teatro B., porque esto no se traduce en ninguna norma relativa a la prestación del servicio ni se fijan las tarifas de la misma ni los plazos y condiciones de su re. visión, conforme exige imperativamente el apartado b) del artículo 163 de la Ley de Régimen local».

(10) Aranzadi 37. 
Considerando 3.०: "Que tampoco cambia la naturaleza civil del contrato de referencia la existencia de las cláusulas cuarta, quinta y séptima, que no pueden considerarse como exorbitantes, entendiendo por tales las que exceden o rebasan la órbita del contrato civil con actos de imperio, porque no lo son las reservas de algunas fechas por parte del Ayuntamiento para dedicar el teatro a festejos y fines culturales; antes bien, esto arguye en contra de lo que se pretende, pues viene a indicar que este concreto servicio público de tipo cultural es lo extraordinario y anormal. Y en cuanto a la censura de espectáculos para evitar que se exhiban los inmorales, antipatrióticos o antiestéticos, que ya se ejerce por el Estado con caracteres de generalidad, la prohibición indicada se entiende implícita por conformidad con las normas penales y de policía, apareciendo por lo demás que, cumplidas estas limitaciones, que no rebasan la órbita de un contrato normal, el arrendatario, con el pago de la renta, disfruta del local y sus instalaciones a su arbitrio y sin contemplación alguna al servicio público».

En sentencia de 30 de septiembre de 1967, la Sala 1. (Aranzadi 3.834) resuelve de oficio la cuestión de la competencia -en cuanto quedó firme el auto desestimatorio del Juzado de primera instancia de la excepción dilatoria- y se califica de civil una cuestión planteada en materia de viviendas de renta limitada (11).

En la sentencia se resolvió cuestión planteada entre una Caja Municipal de Ahorros y una constructora contra varios particulares, titulares de contratos de opción de viviendas. El Tribunal Supremo recurre a la calificación directa del contenido del contrato para deducir la competencia correspondiente.

Cabe citar finalmente la sentencia de 19 de febrero de 1958, también de la Sala 1. ${ }^{a}$ (Ar. 1.030), en la que no existe una referencia a la Ley de la Jurisdicción, por ser la litis anterior a la misma (12).

(11) Considerando $1.0^{\circ}$ : «... sin que obste la facultad de conocer este Tribunal de oficio de la competencia por razón de la materia, pues no existe fundamento para ello, teniendo (en cuenta) que la acción no es estrictamente una cuestión sobre materia administrativa, sino que esencialmente tiene un contenido civil, $\mathrm{y}$, en scgundo lugar, que lejos de desconocer la resolución recurrida, la facultad de la Administración y, por tanto, la eficacia en su día de las sentencias que se dicten en procedimiento contencioso-administrativo, contiene la explicita salvedad sobre el valor de dichas resoluciones para la determinación de los precios definitivos de las viviendas, y se limita a resolver acerca de la eficacia en este momento de las cédulas de calificación, basándose en los artículos 116 de la Ley de Procedimiento administrativo, respecto a que la interposición de cualquier recurso no suspenderá la ejecución del acto impugnado y el artículo 122 de la Ley de 27 de diciembre de 1956, que contiene igual doctrina respecto al recurso contenciosoadministrativo, todo lo que conduce a desestimar el motivo que se examina".

(12) Aranzadi 1.030. Considerando 1.:: "Que la calificación de los contratos administrativos, dierenciándolos de los civiles, es tarea doctrinal ardua, ya que desde negarles sustantividad hasta crear una terminante especialización, se esgrimen largos razonamientos cuya principal base para lograr esa distinción, que 
En dicha sentencia se califica de administrativo un contrato de suministro al ejército, en base del jus imperii del Estado y de la posición de superioridad del mismo.

\section{CONCLUSIONES}

El estudio casuístico de la jurisprudencia del Tribunal Supremo nos permite marcar una clara diferenciación de posturas de las Salas contenciosas y de la Sala $1 .^{\text {a }}$ de lo civil.

Las primeras tienden a estructurar un criterio amplio y extensivo, en base del artículo $3 .^{\circ}$, a), de la Ley de la Jurisdicción, que se sustancia en calificación concreta, de los contratos liminares, como administrativos.

La Sala $1 .^{\mathrm{a}}$, por el contrario, sienta:

a) La adscripción de la contratación al contenido del Derecho privado como principio general.

b) En caso de duda o conflicto, el criterio interpretativo será la tradicional fuerza atrayente de la jurisdicción ordinaria, a no ser que se dibuje claramente el cuadro excepcional de la Ley de la Jurisdicción.

es la de mayor convicción, se dirige, tomados separada o conjuntamente, a la persona de los contratantes, a su manera de actuar, al objeto del contrato, a la finalidad con él perseguida, a la forma de su celebración, a la legislación aplicable, a las consecuencias jurídicas del contrato, a la jurisdicción competente para conocer de ellos $\mathrm{y}$, ateniéndonos a lo legislado y a la doctrina de nuestra jurisprudencia, están perfectamente recogidos los caracteres que determina esa especialización en la sentencia recurrida con referencia al contrato causal de esta "litis", partiendo de las condiciones concurrentes en el mismo, de las que destacan, entre otras, aquellas condiciones referidas al carácter ejecutivo de las disposiciones que la Administración adopte relativas al contrato, salvo los derechos del contratante en vía contencioso-administrativa, al carácter preferente pactado en las disposiciones administrativas en las cuestiones que se susciten y en lo no previsto en el contrato, se regirá éste por los preceptos de la contratación administrativa en el ramo del Ejército, la Ley de Administración y Contabilidad de la Hacienda pública y disposiciones complementarias, a lo que hay que añadir que una de las partes contratantes es la Administración representada por el Intendente Director del Establecimiento Central de Intendencia del Ejército y el Interventor del mismo, actuando en caso urgente, según la referida sentencia, que también afirma el previo acuerdo del Consejo de Ministros emitido dictamen del Consejo de Estado, y que el contrato tenia por objeto la compra y suministro de bienes para el Ejército español, todo lo cual conduce a la acertada estimación de que la intervención del Estado está revestida en el caso del jus imperii, no actúa como simple persona jurídica que la sitúe en posición de igualdad con la otra parte contratante, a la que se le impone una legislación, una jurisdicción, unas condiciones y renuncias y se pacta un verdadero suministro que, contorme a las sentencias que en instancia se invocan, apoyan el buen criterio y acierto en la calificación administrativa del contrato. 


\section{RESEÑA DE SENTENCIAS}

SUMARIO: I. ACTO ADMINISTRATIVO: 1. NulIDAD. 2. NulIDAD: PROCEDimiento EN la AdMINISTRaCión local.-II. BIENES: 1. Deslinde aDMINISTRATIVO: DERECH O DEL COLINDANTE a PEDIRLO. 2. VÍa Pública: OCUPACIÓN PERMANENTE: CONCESIÓN. - III. CONTRATACION ADMINISTRATIVA: OBRAS REALIZADAS al MARGEN DE LO CONTRATADO.-IV. EXPROPIACION FORZOSA: 1. JUSTIPRECIO: ARRENDATARIO DE LOCAL DE NEGOCIO. 2. JUSTIPRECIO: DERECHO ARRENDATICIO: PREMIO DE AFECCIÓN. 3. JUSTIPRECIO: 5 POR 100 DE AFECCIÓN. 4. JUSTIPRECIO: SOLAR QUE SE CONVIERTE EN ZONA VERDE. - V. FUNCIONARIOS: 1. DESTITUCIÓN. 2. MaLVERSACIÓN.-VI. GOBERNADORES CIVILES: Facultad PARA AUTORIZAR EL DERRIBO DE DETERMINADOS EDIFICIOS. - VII. HACIENDAS locales: 1. Arbitrio de plusvalfa: C. A. M. P. S. A. 2. TERRENO EXPROPIADO POSTERIORMENTE. 3. VALOR CORRIENTE EN VENTA. 4. ARBITRIO SOBRE SOLARES SIN EDIFICAR Y ARBITRIO NO FISCAL SOBRE EDIFICACIONES DEFICIENTES. 5. ARBITRIO SOBRE URBANA EN ZONA FRANCA. 6. DEREC H OS Y TASAS: INSTALACIÓN DE MOTORES. - VIII. JURISDICCION CONTENCIOSO-ADMINISTRATIVA: DESVIACIÓN DE PODER.IX. POLICIA MUNICIPAL: 1. DERECHO DEL PROPIETARIO A EDIFICAR: LIMITACIONES. 2. RUINA: CONCEPTO. 3. COMPETENCIA PARA HACER LA DECLARACIÓN.-X. PROCEDIMIENTO ADMINISTRATIVO: 1. RECURSO DE REPOSICIÓN. 2. RECURSO DE REPOSICIÓN: PLAZO.-XI. RESPONSABILIDAD DE LA ADMINISTRACION: ARTículo 40 DE LA LEY dE REgIMEN JURÍdico de la AdMINISTRACIÓN DEL ESTAdo.-XII. SEGURIDAD SOCIAL: AyUntamientos: cuota empresarial en la Seguridad SOCIAl AGraria.-XIII. SERVICIOS: 1. MERCados: SUbIDA DE TARIFAS: aUdienCIa de los interesados. 2. Teléfonos: Cabina en VÍa pública MUNICIPAL.-XIV. URBANISMO: Planes DE ORDENACIÓN: APROBaCIÓN CONDICIONADA.-XV. VIVIENDAS: FacUlTades dE laS aNTIGUAS FISCAlfas de la Vivienda, hoy Delegaciones Provinciales de la Vivienda.

\section{ACTO ADMINISTRATIVO}

1. Nulidad

ConsIDERANDO: Que si bien todo acto administrativo viciado en sus elementos de fondo o de forma, supone un actuar de la Administración 
en contra de lo dispuesto en un precepto legal, por lo que en principio parecería aplicable al mismo el artículo $4 .^{\circ}$ del Código civil, que decreta la nulidad absoluta de los actos ejecutados contra lo dispuesto en la Ley, sin embargo, este principio legal exactamente aplicable al Derecho privado, no lo es al Derecho administrativo, en el que, de serlo, no se podría contemplar otra nulidad que la absoluta, ya que el acto viciado siempre está infringiendo un precepto legal, y por ello, en razón a los distintos principios informativos de ambos Derechos, cuando en el administrativo se produce la infracción del ordenamiento jurídico, no opera como norma corriente la nulidad absoluta decretada en el artículo $4 .^{\circ}$ diel Código civil, sino que la regla general es la anulabilidad y la excepción la nulidad radical que tiene lugar en los términos tasados y exhaustivos enumerados en el artículo 47 de la Ley de Procedimiento administrativo, según lo ha entendido con la doctrina científica la jurisprudencia del Tribunal Supremo en sentencias de 7 de marzo de 1963 y 23 de octubre de 1964. (Sentencia de 11 de febrero de 1975, Aranzadi 479).

\section{NULIDAD: PROCEDIMIENTO EN LA ADMINISTRACIÓN LOCAL}

Considerando: Que de modo acorde con la propia índole de la legislación supletoria, debe entenderse aplicable a las Corporaciones locales la revisión de oficio regulada en la Ley de Procedimiento administrativo, teda vez que el ordenamiento específico de la esfera local no previene los distintos supuestos de invalidación, y taxativamente dispone el artículo 1. , número 4, de la Ley mencionada la aplicación supletoria de referencia, definiéndose así el verdadero problema a resolver, puesto que el Consejo de Estado es Supremo Cuerpo Consultivo de la Administración central, en si el previo y favorable dictamen del mismo, requerido para las invalidaciones de oficio por la Ley de Procedimiento administrativo es también pertinente en punto a Corporaciones locales, o debe ser sustituido por otro del Servicio de Inspección y Asesoramiento de aquellas Corporaciones, o bien por el del Colegio de Abogados o el de un Letrado distinto del consistorial, pero teniendo en cuenta la indirecta posibilidad de acceso de estas materias al Consejo de Estado por medio del Ministerio de la Gobernación, como alto organismo supervisor y tuitivo a través de los servicios de inspección y asesoramiento, y tratarse de cuestiones para las que, desde el lado unificador de criterios con los seguidos respecto a la Administración central, resulta especialmente idónea la garantía del Consejo de Estado, corresponde llegar al planteamiento alternativo de que el artículo 109 de la Ley de Procedimiento administrativo o no se aplica a las Corporaciones locales o si así se hace habrá de serlo en su integridad, con todos los requisitos que en la ratio legis configuraron su texto en armonía con su finalidad, protectora ciertamente del ordenamiento jurídico, pero también instauradcra de garantías para el administrado y para la misma Administración, que mientras el Gobierno no actúe sobre la materia, lo establecido 
en la disposición final $4 .^{a}$ de la Ley de Procedimiento administrativo, preferentes habrán de ser las unívocas lege data, que las inseguras, aunque valiosas, soluciones doctrinales, propias de construcción lege feren$d a$, en orden a definir para la esfera local un dictamen sucedáneo del que la legislación supletoria exige del Consejo de Estado con la cualificación de favorable, razones que inducen a resolver la antecitada alternativa en el sentido de que también la revisión de oficio de propios actos por las Corporaciones locales requiere previo dictamen favorable de aquel alto organismo consultivo para legitimar procesalmente la decisión, cuyo dictamen, por obvias razones de acoplamiento al ámbito funcional del Consejo de Estado, deberá solicitarse del mismo por el Ministerio de la Gobernación si éste lo estima oportuno a instancia de la Entidad local correspondiente. (Sentencia de 9 de diciembre de 1974, Aranzadi 5.025).

\section{B I E N E S}

\section{Deslinde administrativo: DERECH O DEL COLINDANTE}

\section{A PEDIRLO}

Considerando: Que desde un ángulo estrictamente jurídico, procede proclamar que el deslinde de fincas limítrofes constituye un medio de defensa que se otorga por la Ley a todo propietario, para asegurar la inviolabilidad de los confines o límites de objeto de su dominio, constituyendo en consecuencia un poder jurídico derivado del derecho de propiedad y concebido como una de las facultades que integran el contenido de dominio, con la finalidad de identificación de la cosa sobre la cual se ejercita.

Considerando: Que en consecuencia procede la operación de deslinde, a petición de cualquiera de los propietarios afectados, siempre que exista una situación de incertidumbre en los confines de dos o más fincas limítrofes, implicando tal operación de deslinde una actividad declaratoria en cuanto proyecta sus efectos de delimitación exacta de los linderos sobre el terreno, y que se complementa con la operación subsiguiente, ejecutiva, de amojonamiento para fijar la delimitación efectuada.

Considerando: Que esta facultad que la Ley concede a todo propietario, según el artículo 384 del. Código civil, es ejercitable frente a los propietarios de los fundos colindantes, incluso en el supuesto de que éstos pertenezcan a la Administración pública, y aunque los bienes tengan carácter demanial, pues tal titularidad únicamente afecta a que el procedimiento de deslinde, en tales casos, tiene lugar por un procedimiento genuinamente administrativo, correspondiendo a la propia Administración la facultad de efectuar las correspondientes operaciones 
de deslinde, resolviendo unilateralmente y con exclusividad, sin perjuicio de los recursos procedentes contra las decisiones adoptadas en esta materia.

Considerando: Que en perfecta congruencia con la doctrina expuesta, el Reglamento de Bienes de las Entidades locales en su artículo 44 determina, por un lado, que dichas Corporaciones tendrán la facultad de promover y ejecutar el deslinde entre los bienes de su pertenencia - sin distinguir, por lo tanto, entre patrimoniales y demaniales- y los de los particulares cuyos límites aparecieran imprecisos o sobre los que existiesen indicios de usurpación, y por otra parte, el mismo precepto en su apartado $2 .^{\circ}$ establece que los dueños de terrenos colindantes con fincas pertenecientes a las Entidades locales, o que estuvieren enclavados dentro de aquéllas, podrán reclamar su deslinde, lo que inequívocamente legitima a los particulares que se encuentren en dicha situación, para interesar de la Administración local la práctica del deslinde, que en tal caso no constituye facultad discrecional, sino obligación municipal frente a sus administrados. (Sentencia de 14 de diciembre de 1974, Ar. 5.135).

\section{Vfa PÚBliCA: OCUPACIÓN PERMANENTE: CONCESIÓN}

Considerando: Que la problemática jurídica que plantea el presente recurso exige, como presupuesto previo, el análisis de la naturaleza o carácter jurídico que quepa atribuir al objeto del acto administrativo de autorización de la instalación o construcción levantada en la acera este del paseo del Generalísimo de la ciudad de Almería, frente a la finca urbana número 65 de dicha calle, con una extensión superficial de 61,30 metros cuadrados (ocupando más del 50 por 100 de la superficie de la acera, en una longitud de 17,10 metros) a favor de la señora C. P., como titular del Bar o Café H., situado en la finca expresada, modificando esencialmente el anterior permiso de ocupación de acera (vía pública) con veladores y sillas, al transformarlo en un local cerrado, independiente y apto para la explotación comercial permanente de caféterraza.

Considerando: Que la construcción y explotación de un local de las características del de autos sobre el dominio público municipal supone indudablemente una atribución o facultad de utilización (disfrute) a un particular que merece la conceptuación de "uso privativo" por cuanto implica la ocupación del dominio (61,30 metros cuadrados de acera), de forma que impide la utilización de tal espacio por los demás; aparte de significar también un "uso anormal» al excluir la libre circulación que debe estimarse como fin primario de la vía pública o calle, y todo ello gravado por el hecho o dato que comporta la instalación levantada en la acera (transformación), en cuanto no representa un mero estar sobre el dominio (el llamado por la doctrina «estacionamiento» y que la prác- 
tica con infracción del artículo $62,1, b$ ), del Reglamento de Bienes, permite otorgar mediante la técnica de la autorización o licencia), sino que supone una ocupación permanente del dominio público hecha posible por la edificación levantada a tal fin y cuya existencia jurídica se hace depender, con criterio unánime, del régimen jurídico de la concesión administrativa (artículo 62, 1, 1, del Reglamento). (Sentencia de 31 de enero de 1975, Ar. 448).

\section{CONTRATACION ADMINISTRATIVA}

\section{ObRas REALIZADAS AL MARGEN DE LO CONTRATADO}

Considerando: Que procede la confirmación de dicho último punto porque, aun tratándose evidentemente de obras ajenas a la contrata y, en consecuencia, no obligadas en principio la Corporación a satisfacerlas si se hubieren realizado unilateralmente por el contratista, es lo cierto que aparece en autos probado e incluso no contradicho en general que dichas obras se efectuaron por virtud de órdenes escritas unas veces y otras verbales del Alcalde, tal como se desprende, por una parte, de la recepción provisional sin objeción al respecto $\mathrm{y}$, por otra, de la certificación de los Arquitectos directores, corroborada por la prueba pericial y la propia certificación municipal acreditativa de que parte al menos de las modificaciones fueron ordenadas de modo amplio, y en cuanto a las demás, no negadas las órdenes que los directores aseguran haber recibido, el dictamen pericial de autos determina la ejecución por el importe certificado y su necesidad técnica para la global ejecución del edificio; y si bien es cierto que, a tenor del artículo 54 del Reglamento de Contratación de las Corporaciones locales, la potestad de éstas para modificar las prestaciones contratadas debe llevarse a cabo mediante los requisitos de procedimiento y dentro de las limitaciones cuantitativas allí prescritas, no lo es menos que sí fueron ordenadas al contratista y ejecutadas por éste, los vicios que resulten del incumplimiento de aquellas prescripciones por la Corporación no deberán perjudicarle, puesto que su incumplimiento no le es imputable y, por consiguiente, podrá percibir su importe, sin perjuicio de la responsabilidad en su caso exigible por la Corporación a quien las hubiere acordado $u$ ordenado ilegalmente; procede por ello confirmar también en este punto el criterio de la sentencia apelada en cuanto entendió no ajustada a Derecho la desestimación presunta de la reclamación de la suma certificada por estas obras. (Sentencia de 16 de diciembre de 1974, Ar. 5.218). 


\section{EXPROPIACION FORZOSA}

\section{JUSTIPRECIO: ARRENDATARIO DE LOCAL DE NEGOCIO}

Considerando: Que el artículo 47 de Ley de Expropiación forzosa establece que en todos los casos de expropiación se abonará al expropiado, además del justiprecio, un 5 por 100 como premio de afección, y el artículo 47 del Reglamento de dicha Ley preceptúa que las indemnizaciones debidas a los arrendatarios en caso de privación definitiva para los mismos del uso y disfrute de los bienes o derechos arrendados... se incrementará también en el premio de afección, premio que, según las sentencias de 19 de enero, 7 de febrero, 6 de mayo, 4 de septiembre y 20 de octubre de 1972, ha de calcularse sobre el importe total de la indemnización correspondiente al titular del derecho arrendaticio expropiado, sin distinguir las diferentes partidas relativas a los diferentes conceptos computables, y de ahí que deba el Tribunal modificar respecto a tal extremo el justiprecio fijado por el Jurado, donde se sigue la tesis de repercutir el 5 por 100 sobre la partida principal (capitalización de la diferencia de rentas), pero no sobre las otras partidas (gastos de traslado), doctrina que no es la que prepondera en la jurisprudencia de nuestro más Alto Tribunal. (Sentencia de 27 de febrero de 1975 , Ar. 808).

\section{JUSTIPRECIO: DERECHO ARRENDATICIO: PREMIO DE AFECCIÓN}

Considerando: Que esta Sala, interpretando los artículos 47 de la Ley de Expropiación forzosa del 16 de diciembre de 1954 y de su Reglamento de 26 de abril de 1957, reguladores del 5 por 100 del premio de afección, ha establecido una dístinción según que se abone al propietario del bien expropiado o que se trate de la indemnización que corresponda al arrendatario que sufre la expropiación, la privación definitiva del uso y disfrute de la vivienda o local de negocio objeto de la relación contractual arrendaticia, en méritos de la cual y contemplando uno y otro supuesto, ha consagrado para el primero la doctrina (sentencias de 5 de mayo y de 8 de junio de 1971 y 3 de mayo de 1972, entre otras) limitativa del premio de afección al estricto justiprecio atribuido al titular del derecho expropiado de que se le priva y exclusión de cualquier indemnización que por otro concepto le sea concedida, y ello por la obvia razón de que teniendo el premio del 5 por 100 naturaleza compensatoria del aprecio subjetivo y meramente afectivo del propietario, inspirándose en los quebrantos espirituales más bien que económicos, que para aquel representa la transmisión imperativa de lo que era suyo, carece de justificación que el premio se extienda a otros conceptos indemnizatorios complementarios y distintos al justiprecio del bien expropiado, e incluso esta misma Sala, en la sentencia de 6 de junio de 
1971, enjuiciando el supuesto de que en la finca expropiada exista instalada una industria, ha establecido un matiz diferencial, concediendo el premio de afección sobre el justiprecio de aquélla, pero no sobre los perjuicios consiguientes; mas, por el contrario, en el caso de traslado de una industria o negocio mercantil, explotado a título arrendaticio, por persona o entidad distinta al propietario del local, se ha mantenido por esta Sala la doctrina consignada en la sentencia de 19 de enero de 1971 y reiterada, entre otras, en las de 7 de febrero, 6 de mayo, 30 de septiembre y 20 de diciembre de 1972, 29 de noviembre y 24 de diciembre de 1973, 4 de abril y 17 de octubre de 1974, de la procedencia de que el premio de afección sea modulado por la totalidad de la valoración indemnizatoria que al arrendatario se concede. (Sentencia de 7 de febrero de 1975, Ar. 528).

\section{JUSTIPRECIO: 5 POR 100 DE AFECCIÓN}

Considerando: Que en el acuerdo del Jurado se incrementan el justiprecio y el importe de la indemnización con el 5 por 100 de afección -lo que sin razonamiento alguno en sus considerandos se mantiene en la sentencia recurrida-, infringiéndose con ello lo dispuesto en los artículos 47 de la Ley de Expropiación forzosa y de su Reglamento, conforme a los cuales tal premio no corresponde a las indemnizaciones, salvo para los arrendatarios. (Sentencia de 23 de diciembre de 1974, Aranzadi 4.965).

\section{JUSTIPRECIO: SOLAR QUE SE CONVIERTE EN ZONA VERDE}

Considerando: Que tanto los acuerdos del Jurado de Expropiación como la sentencia recurrida parten de la base que la finca número 7 de la calle Cuesta de las Descargas de esta capital tenía originariamente las condiciones intrínsecas para ser conceptuada como "solar", y si bien con la certificación obrante al folio 21 se acreditó que aquélla, al ser aprobado el Plan general de ordenación de Madrid en virtud de lo dispuesto en la Ley de 1 de marzo de 1946 se modificó la expresada calificación urbanística por la de zona verde; no puede olvidarse que como viene manteniendo una reiterada jurisprudencia, la condición de solar existente antes de la aprobación de un plan no puede degradarse en trance de valoración cuando se trata de una transmisión coactiva (sentencias de 19 de mayo de 1967, 6 de abril de 1968, 22 de mayo de 1971, 16 de diciembre de 1972,19 de febrero y 26 de septiembre de 1973 y 5 de abril de 1974 entre otras). (Sentencia de 18 de diciembre de 1974, Aranzadi 4.870). 


\section{FUNCIONARIOS}

\section{Destitución}

CONSIDERAndo: Que a través de todo lo actuado y del informe del Colegio Oficial de Secretarios de la Provincia de Alava se destaca la continua inasistencia del recurrente a las oficinas municipales para prestar los servicios propios de su cargo, que no se halla cubierta por los certificados médicos que reiteradamente y por distintas enfermedades presentaba el actor, que faltaba a numerosas sesiones de la Corporación y tenía retrasada la aprobación de los presupuestos de 1970 y de los expedientes en trámite pese a los numerosos requerimientos verbales del Alcalde y apercibimientos por escrito de dicha autoridad, previo acuerdo de la Corporación, sin que se hubiese obtenido la rectificación de la conducta del recurrente, quien además, disponiendo de casa-habitación en la localidad, infringía el deber de residencia, no pudiendo admitirse la disculpa de que lo hacía porque la casa no reunía condiciones de habitabilidad dignas del cargo, circunstancia que el actor no ha probado por ninguno de los medios que tenía a su alcance.

Considerando: Que los citados hechos han de ser calificados como lo efectuó la Administración, como constitutivos de una falta muy grave del artículo 102, 2, del Reglamento de Funcionarios lorales, de ausencia injustificada del servicio, cualificada por la infracción del deber de residencia, por disponer el inculpado de casa-habitación, y de una falta grave del artículo 105, 2, del mismo Reglamento, de defectuoso incumplimiento en el ejercicio y perjuicio de la Administración, al constituir la demora en la aprobación de los presupuestos municipales un grave detrimento para el desarrollo municipal y que la sanción impuesta de destitución del cargo, con arreglo al artículo 108 del Reglamento de 30 de mayo de 1952, es ajustada a Derecho. (Sentencia de 26 de febrero de 1975, Ar. 801).

\section{MaLversación}

Considerando: Que los auxiliares de la recaudación de impuestos han sido considerados por esta Sala como funcionarios públicos en aplicación del artículo 119 del Código penal, entre otras en las siguientes resoluciones: 18 de noviembre de 1872, 22 de septiembre de 1877, 25 de junio de 1881, 20 de abril de 1882, 13 de noviembre de 1885, 10 de abril de 1889,10 de octubre de 1890,7 de diciembre de 1916 y 3 de junio de 1935, que declararon que la cobranza de las contribuciones es una función del Estado y los que la verifican son funcionarios públicos para todos los efectos del Código penal, tanto los recaudadores de contribuciones, los agentes ejecutivos, como sus respectivos auxiliares. A su vez, las sentencias de 20 de marzo de 1953, 4 de marzo de 1957 y 2 de 
diciembre de 1965 declaran que, aunque el Estado no incorpore a los auxiliares a los escalafones de los funcionarios estatales ni les retribuya directamente, convierte directamente en funcionario público a quien realiza sus funciones lejos del alcance de los simples particulares, pues la calidad de funcionario público del auxiliar está demostrada por la naturaleza pública de las funciones que desempeñan en virtud de nombramiento recaído según las disposiciones del Estatuto vigente, que confiere al Recaudador la facultad de designar a estos auxiliares.

ConsIDERANDo: Que si era funcionario público ejercía funciones públicas, estaba conjuntamente encargado de fondos públicos y sustrajo con el imputado muerto caudales públicos, cometió la malversación tipificada en el artículo 394. (Sentencia de 2 de diciembre de 1974, Aranzadi 4.923).

\section{GOBERNADORES CIVILES}

\section{FACULTAD PARA AUTORIZAR EL DERRIBO DE DETERMINADOS EDIFICIOS}

Considerando: Que en cuanto a la cuestión de fondo planteada en el presente recurso, y recordando el criterio sentado sobre el particular en reiteradas declaraciones del Tribunal Supremo, de las que son expesión, entre otras, las sentencias de 14 y 16 de junio de 1969 , es de tener en cuenta que, tanto el artículo 79 como el 81 de la vigente Ley de Arrendamientos urbanos, al atribuir a los Gobernadores civiles la concesión o denegación de autorización de demolición de edificaciones destinadas a viviendas o locales de negocios para construir otras en su lugar, bien porque el propietario de las mismas proyecta que el nuevo edificio cuente cuando menos con un tercio más de viviendas que el derruido, supuesto previsto en el primero de los preceptos legales citados, o bien, como prevé el segundo de esos preceptos y es del caso presente, debido al estado en que se encuentra el edificio que se propone demoler, para construir otro con el mismo destino, normas jurídicas ésas, como ya se deja indicado anteriormente, que son complemento del artículo 28 del Decreto de 10 de octubre de 1958, sobre atribuciones y deberes de los Gobernadores civiles, señalándoles la específica función de fomentar la construcción de viviendas destinadas a los sectores de población de economía modesta, buscan ante todo la realización de lo que debe ser el interés público o general de la sociedad española, en su proyección dentro de la jurisdicción de aquella autoridad gubernativa, dotándola de una facultad discrecional para apreciar en definitiva en cada caso la medida más oportuna en atención a dicho fin; sin embargo, esta facultad no es absolutamente discrecional e ilimitada, pues los mismos preceptos legales estableciéndola subordinan o condicionan su ejercicio a determinadas circunstancias, sin cuyo análisis o estimación no puede adoptarse legítimamente la medida, algunos de cuyos elemen- 
tos por su contenido técnico, naturalmente, requieren estar aseverados por la opinión de personas expertas en ellos. Por lo que con esta orientación resulta conclusión evidente que la revisión de tales actos $o$ acuerdos en la presente jurisdicción contencioso-administrativa ha de circunscribirse a determinar si hubo desviación de poder o error material al adoptarlos. (Sentencia de 27 de noviembre de 1974, Ar. 4.997).

\section{HACIENDAS LOCALES}

\section{Arbitrio de plusvalfa: C.A. M. P.S. A.}

ConsIDERando: Que sin necesidad de entrar a examinar la procedencia de equiparar la C.A.M.P.S. A. al Estado, en atención a ser administradora del Monopolio de Petróleos, es lo cierto que en el caso concreto objeto del recurso no puede ser aplicable la exención que para el arbitrio municipal sobre Incremento del Valor de Terrenos establece el artículo $520, a)$, de la Ley de Régimen local, porque, según su párrafo $3 .^{\circ}$, «el derecho de exención habrá de referirse siempre a la persona o entidad sobre la que recaiga el arbitrio, a tenor de los preceptos del artículo 517, con total ábstracción de la persona obligada al pago", que en esta clase de transmisiones a título oneroso lo es el adquirente, a tenor del artículo $518, b$ ), de la misma Ley, y, por lo tanto, la Compañía Arrendataria del Monopolio de Petróleos, Sociedad Anónima, sin perjuicio del derecho de repercutir sobre el enajenante el importe del gravamen, a tenor del apartado $b$ ) del mismo precepto. (Sentencia de 18 de diciembre de 1974, Ar. 4.955).

\section{TERRENo EXPRopiado POSTERIORMENTE}

Considerando: Que reconocido por la entidad contribuyente que la expropiación forzosa tuvo lugar el día 19 de diciembre de 1965, hasta cuyo momento es incuestionable (artículos 36 y 53 de la Ley de Expropiación forzosa y 60 del Reglamento) que era propietaria de los $952.5 n$ metros cuadrados expropiados no cabe hacer la deducción de los mismos al gravar la finca con el arbitrio sobre incremento de valor de los terrenos en su modalidad de Tasa de Equivalencia por el período de 1 de enero de 1955 a 31 de diciembre de 1964, ya que a lo largo de todo el período impositivo y cuando conforme al artículo 518 de la Ley de Régimen local, nació la obligación de contribuir (1 de enero de 1955) aquella porción, como se dice le pertenecía cualquiera que fuesen las limitaciones a que venía sujeta por obra del expediente expropiatorio y la propia entidad en tal carácter de propietaria y beneficiaria de los incrementos de valor hasta el expediente de justiprecio, era en ese momento sujeto pasivo del arbitrio conforme al artículo 54 del Reglamento de Hacienda municipal de Madrid, de 17 de diciembre de 1964. (Sentencia de 19 de diciembre de 1974, Ar. 4.999). 


\section{VALOR CORRIENTE EN VENTA}

Considerando: Que el concepto de valor corriente en venta, como contenido en el artículo 511 de la Ley de Régimen local, se antepone siempre a las normas del Indice de valoración y de la Ordenanza fiscal respectiva, y de ahí que si el terreno sometido al arbitrio sobre el incremento del valor es de gran extensión o de gran fondo, de tal suerte que, después de constituida una parcela de fondo normal, sobre la calle de mayor valor, hay todavía la posibilidad de formar otra $u$ otras parcelas sobre las restantes calles o linderos, el valorar únicamente por la calle principal, aunque el Indice y la Ordenanza lo autoricen, supone menoscabo del expresado concepto legal, y no puede calificarse de proceder jurídicamente correcto; como así se viene manteniendo por esta Sala en sentencias de 21 de abril, 7 de julio y 11 de noviembre de 1969, 13 de marzo y 7 de octubre de 1970, 24 de marzo y 29 de abril de 1971 y 22 de enero, 16 de mayo, 18 de octubre y 28 de noviembre de 1974. (Sentencia de 31 de enero de 1975, Ar..319).

\section{ARBITRIO SOBRE SOLARES SIN EDIFICAR Y ARBITRIO NO FISCAL SOBRE EDIFICACIONES DEFICIENTES}

Considerando: Que el arbitrio sobre solares sin edificar, origen de las liquidaciones litigiosas, está regulado por el artículo 499 y siguientes de la Ley de Régimen local vigente de 24 de junio de 1955, con independencia de los arbitrios confines no fiscales regidos por el artículo 473 y siguientes, de la misma Ley, cuyo precepto bajo el número 4 menciona entre otros arbitrios con fines no fiscales los relativos a solares insuficientemente edificados, apareciendo así este último arbitrio del artículo 473, formando parte de la Sección III, del Capítulo V del Títu. lo primero del Libro IV de la referida Ley, mientras que el arbitrio sobre los solares sin edificar ya indicado a que se refiere el artículo 499 forma parte de la Sección IV del mismo Capítulo, por lo que en la estructura y sistemática legal se muestran ambos arbitrios con propia sustantividad y naturaleza diferente, cualquiera que sea la similitud que puedan presentar en algunos de sus aspectos comunes de fomento de la edificación, por lo que a los efectos de la legalidad de esta exacción del arbitrio sobre los solares sin edificar, bastará que se den los supuestos fácticos previstos en la citada norma del artículo 499 de la repetida Ley de Régimen local, sin que las motivaciones intrínsecas que se suponga hayan impulsado al legislador a su implantación sean suficiente razón para la no aplicación de una norma legal cuando se den sus presupuestos. (Sentencia' de 20 de enero de 1975, Ar. 66). 


\section{ARBITRIO SOBRE URBANA EN ZONA FRANCA}

ConsIDERANDo: Que, como ya se apuntaba, al no existir en la especial normativa fiscal de la zona franca más casos de no sujeción y exención que los señalados, nada obsta fuera de ellos a la obligatoria aplicación en las mismas de la potestad fiscal del Estado o de los Entes locales; a cuyas normas generales hemos de atenernos y que son perfectamente armonizables con aquel excepcional régimen tributario, siempre de interpretación estricta; y así se rige en la materia que nos ocupa el principio de generalidad fiscal consagrado no sólo en la Ley General Tributaria, sino también en el artículo 719 de la Ley de Régimen local, en cuanto dice que la obligación de contribuir es siempre general en los límites de esta Ley, y, en consecuencia, ni las Corporaciones locales ni el Gobierno podrán declarar otras exenciones que las concretamente previstas y autorizadas en ella, debiendo entenderse por expresamente denegada toda otra exención actualmente en vigor, aunque se funde en razones de equidad o analogía; y si bien debe entenderse que este precepto general, no deroga el especial régimen tributario de las zonas francas, es lo cierto también que éste sólo excepciona a los tributos que graven directamente las mercancias introducidas o transformadas en dichas zonas, $y$, por lo tanto, no afecta al arbitrio municipal sobre la riqueza urbana aquí discutido, que no opera de modo directo sobre las meritadas mercancías y sí sobre los terrenos de la zona franca de Vigo, en donde está instalada la Factoría Citroen Hispania, S. A., arbitrio perfectamente exigible en virtud de la Ley de Régimen local y la oportuna Ordenanza número 75 del Ayuntamiento de Vigo, ya que a tenor del artículo 558 de dicha Ley sujeta a los mismos conceptos sometidos a la Contribución Territorial Urbana, al cual serán aplicables las exenciones. (Sentencia de 26 de diciembre de 1974, Ar. 5.086).

\section{DERECHOS Y TASAS: INSTALACIÓN DE MOTORES}

Considerando: Que la doctrina jurisprudencial de la Sala en relación con la materia de litis - tasa por inspección de motores e instalaciones mecánicas e industriales- declarada últimamente en las sentencias de 28 de febrero de 1970, 13 de febrero, 1 de marzo y 2 de noviembre de 1971 y 21 de septiembre de 1972, ha establecido, entre otros, los siguientes puntos de doctrina: 1) Que debe tenerse, en todo caso, presente que para la legitimidad de las exacciones que por el concepto expresado pueden imponer los Ayuntamientos, es requisito condicionante la "efectiva utilización del servicio", prevenida en el artículo 436 de la Ley de Régimen local; 2) Que, por consiguiente, la mera existencia de dicho servicio no faculta, en modo alguno, para la exacción de estos gravámenes; 3) Que la visita de inspección debe, en consecuencia, "realizarse» comprobando que los motores se encuentran en buen estado de funcionamiento y que las instalaciones ofrecen garantías de seguri- 
dad y salubridad, por lo que no es bastante a los efectos referidos hacer una sucinta relación de máquinas y girar en su visita una liquidación; 4) Que dicha visita de inspección debe además «acreditarse» con la consignación de los detalles necesarios, la firma del Ingeniero visitante y además la del representante de la empresa visitada, o la de dos testigos en su defecto, y 5) Que todo esto se exige para evitar, como declara la sentencia de esta Sala de 26 de octubre de 1965, que se conviertan estas tasas por "efectiva prestación de servicios" en verdaderos arbitrios municipales, contra la legalidad vigente. (Sentencia de 20 de enero de 1975, Ar. 65).

\section{JURISDICCION CONTENCIOSO-ADMINISTRATIVA}

\section{DESVIACIÓN DE PODER}

La desviación de poder o violación de la ley pueden servir de fundamento a las pretensiones de anulación y a las de plena jurisdicción y nuestro Tribunal Supremo en reiteradas sentencias ha declarado al hablar de esta figura jurídica, que supone un ánimo predeterminado de utilizar la facultad de obrar con fuerza de obligar que los órganos de la Administración ostentan, orientándolo hacia la consecución de objetivos no previstos concretamente por la motivación legal, que inspira la norma que se aplica, aun cuando al hacerlo se observen las formalidades exigidas para su legitimación, sentencias de 24 de octubre de 1959, 28 de febrero de 1962, añadiendo que la desviación existe cuando el acto se inspira en móviles personales o en cualquier otra causa de ilegalidad (sentencia de 14 de mayo de 1959, y que tal figura pertenece a la esfera de la ética, tendiendo a descubrir la antinomia entre legalidad y derecho (sentencia de 1 de junio de 1959), especificando que el acto no debe contravenir el sentido teleológico de la actividad administrativa que ha de reputarse orientada siempre a la promoción del interés público y sometida a un sistema de norma legal, y del mismo modo que los actos de los particulares se presumen de buena fe, los de la Administración han de admitirse en principio como legítimos cuando trata de atacarse uno de ellos será necesario probarlo, por lo cual la sentencia de 14 de mayo de 1959 rechaza el recurso, porque no constan en las actuaciones elementos de convicción demostrativos del aserto en que se basa la demanda, y la de 26 de diciembre de 1960 insiste en la necesidad de la prueba, siendo necesario acreditar con seguridad que la Administración se apartó del cauce jurídico, ético y moral, y la de 7 de octubre de 1963 indica que la desviación no ha de fundarse en meras presunciones y en suspicacias ni especiosas interpretaciones del acto de autoridad, sino en hechos concretos, y la de 3 de julio de 1963 añade que, en todo caso, para apreciarla es menester una demostración clara y palmaria de que el ejercicio de las potestades administrativas se verificó torcidamente, sin consideración al motivo o finalidad pre- 
establecido para el bien o interés público, y la de 24 de febrero de 1971 indica que para que pueda estimarse la desviación de poder es necesario, como la doctrina jurisprudencial tiene establecido, que se acredite, o cuando menos se señale, datos de hecho o elementos de com. probación externa capaces de crear, mediante un juicio comparativo entre el fin específico o de interés público a que el precepto o preceptos concretos que se aplican al fin que sea perseguido con los actos impugnados, la convicción de que el órgano administrativo al que se atribuye tal vicio se apartó del cauce jurídico a que estaba obligado a seguir ateniéndose al espíritu y finalidad de la norma aplicada. (Sentencia de 17 de enero de 1975, Ar. 4).

\section{POLICIA MUNICIPAL}

\section{DERECHO DEL PROPIETARIO A EDIFICAR: LIMITACIONES}

Considerando: Que si, en efecto, el derecho a edificar en terreno propio constituye una de las facultades singulares del derecho de pro piedad, este derecho no es tan absoluto que carezca incluso de los límites que por definición corresponden al dominio y son reconocidos expresamente por el artículo 348 del Código Civil, al definir al derecho de propiedad como al derecho de gozar y disponer de una cosa «sin más límites que los establecidos en las leyes», siendo el propio Código el que admite expresamente en el artículo 459 servidumbres sobre él, impuestas por la Ley por utilidad pública», limitaciones o servidumbres, añade, que «se regirán por las leyes y reglamentos especiales que los determinan", habiéndose acentuado extraordinariamente este sentido social público del dominio por la evolución del Derecho nuevo en su relación con el clásico o tradicional a impulso del progresivo desarrollo del Derecho social y los servicios públicos, que son seguramente la faceta más característica del progreso del Derecho privado en su transformación ineludible en Derecho público, como lo demuestra el Fuero del Trabajo (declaración XII), el Fuero de los Españoles (número 3), la Declaración de los Principios fundamentales del Movimiento $(\mathrm{X})$, en que se reconoce a la propiedad privada como un derecho condicionado a la función social, y ha sido el desarrollo de este sentido social o funcional de la propiedad el que ha inspirado el Régimen jurídico del Suelo y Ordenación urbana - Ley de 12 de mayo de 1956, fundamental en la materia en litis-; la Ley de 7 de julio de 1911, completado por su Reglamento de 1 de marzo de 1912, en favor de la investigación y conservación de antigüedades, así como las disposiciones protectoras del Patrimonio Artístico e Histórico Nacional - Ley de 13 de mayo de 1933 y Reglamento de 16 de abril de 1936- y el Decreto de 22 de julio de 1958, por no citar más que disposiciones afectadas al caso en cuestión, todas las cuales subordinan el derecho de propiedad en general y a sus facultades en concreto, al servicio del bien común 
o de los intereses generales de utilidad pública, contándose entre ellas la de edificar, que, naturalmente, ha de operar siempre bajo la consigna de servir o de no perjudicar al interés público preponderante sobre el privado o coincidentes con él, con todo lo cual queda bien justificada la actuación de cuantos Organismos administrativos han intervenido en este expediente, desde el Ayuntamiento de Mérida hasta la Presidencia del Gobierno, pasando por el Ministerio de Educación y Ciencia, como defensores del Patrimonio Artístico Histórico Nacional. (Sentencia de 21 de diciembre de 1974, Ar. 5.009).

\section{RUINA: CONCEPTO}

Considerando: Que consecuentemente el concepto legal de estado ruinoso, aplicado a las construcciones o edificaciones, es más amplio que el término vulgar o estrictamente técnico de la ruina, pues así como éste se concreta en las construcciones derruidas o con peligro cierto de destrucción o pérdida, la Ley, en el precepto citado, asimila a la ruina, las edificaciones que, sin riesgo inmediato de caída o desplome, necesitan para dejarlas en una situación normal de uso y aprovechamiento, la realización de reparaciones cuyo costo rebasa el tope legal indicado, siendo indiferente a estos efectos la naturaleza de los desperfectos o deterioros que ofrezca el inmueble, pues aun cuando no afecten de forma directa a los elementos principales o sustentadores, no debe olvidarse que el criterio legal se inspira, como se ha dicho, en consideraciones de orden económico, aparte de que dada la unidad arquitectónica existente entre todos los elementos que componen la construcción, los daños en los elementos secundarios, al alcanzar una gran extensión facilitan, a la larga, la destrucción de los de carácter principal, con lo cual aun en estos casos se presenta un riesgo de ruina propia, aunque de forma más remota o mediata. (Sentencia de 21 de diciembre de 1974, Ar. 5.171).

\section{COMPETENCIA PARA HACER LA DECLARACIÓN}

Si bien la doctrina jurisprudencial de esta Sala, hubo un tiempo que estuvo fluctuante en relación con la competencia de los Alcaldes en esta materia, admitiéndola en determinados casos y en otros estableciendo que correspondía a la Comisión Municipal Permanente; sin embargo, a partir de sentencias de 23 de junio de 1970, en especial en la de 26 de enero de 1973, que recoge otras anteriores de 25 de octubre de 1957, 24 de marzo y 22 de diciembre de 1958, 23 de septiembre de 1960, 7 de julio de 1961, 20 de febrero de 1962 y 10 de mayo de 1969 , más la de 5 de octubre de 1974, con claridad meridiana viene distinguiendo entre las declaraciones de estado ruinoso en expediente contradictorio y las declaraciones de inminente urgencia, ya que en las primeras 
corresponden al Ayuntamiento en su Comisión Permanente, según el sentido jurisprudencial, y por el procedimiento adecuado, atribuyendo prudencialmente a un órgano colegiado y no unipersonal la responsabilidad de tal decisión, tanto por garantía de los administrados como por descargo de la primera autoridad municipal respecto a tan trascendente decisión, si bien es a ésta a quien corresponde la dirección de la tramitación del expediente, con arreglo al artículo 114, núm. 10, de la Ley de Arrendamientos urbanos y del 58 de la Ley de Régimen local, tema completamente distinto de la declaración de ruina inminente, a que se contrae el núm. 4 del artículo 170 de la Ley de Régimen del Suelo y Ordenación urbana de 12 de mayo de 1956, en el cual la referencia ha de entenderse a la urgencia y peligro, tal como en el mismo se dice señalando así una tramitación, también de urgencia, completamente distinta a la del expediente contradictorio y atribuyendo la competencia en tales casos, bien al Ayuntamiento, bien a la autoridad unipersonal del Alcalde. (Sentencia de 27 de enero de 1975, Ar. 446).

\section{PROCEDIMIENTO ADMINISTRATIVO}

\section{RECURSO DE REPOSICIÓN}

Considerando: Que el segundo de los motivos de nulidad alegados por la parte actora se deriva del hecho de que la Corporación municipal no indicó al actor que contra el acuerdo de inclusión de la finca en el Registro de Solares el recurso procedente era el de reposición ante el propio Ayuntamiento, concediéndole en cambio el de alzada ante la Comisión Provincial de Urbanismo -que ejercitó-, por lo que se infringió lo establecido en el artículo 217 de la Ley sobre Régimen del Suelo y Ordenación urbana y la doctrina contenida en las sentencias del Tribunal Supremo de 13 de enero y 5 de mayo de 1969.

Considerando: Que el problema que plantea el actor en este segundo motivo de nulidad ha sido objeto de larga polémica doctrinal, puesto que mientras que algún sector de la doctrina estima que el artículo 217 de la Ley sobre Régimen del Suelo -que exigía el recurso de reposición previo al de alzada - ha sido derogado por la Ley de Procedimiento administrativo y en parte por el Reglamento de Solares - pese al distinto rango del precepto-, en cambio, otro sector alegaba que el artículo 217 se hallaba vigente, y que, por tanto, y en todo caso, mientras no existiera una derogación expresa, debía de seguir aplicándose y, por tanto, procedía entablar el recurso de reposición previo al contencioso-administrativo; igual incertidumbre existe al respecto sobre la vía que debe seguirse, si nos atenemos al criterio seguido por la Jurisprudencia del Tribunal Supremo, ya que, a favor de la derogación del artículo 217 de la Ley sobre Régimen del Suelo se pronuncian, entre otras, las sentencias de 13 de enero, 18 de marzo y 15 de abril de 1964, 
26 de mayo y 12 de noviembre de 1965, 22 de enero y 16 de febrero de 1966, 10 de abril de 1968 y 6 de junio de 1970, mientras que otro grupo de sentencias se pronuncian en sentido contrario, admitiendo la plena vigencia del artículo 217 de la Ley del Suelo, y, por tanto, la exigencia del recurso de reposición como previo a la alzada, siendo ejemplo de ello las de 13 de enero y 5 de mayo de 1969 y 19 de mayo de 1970.

Considerando: Que ante tal diversidad de opiniones, doctrinales y jurisprudenciales (destacándose el hecho de que entre algunas de las sentencias citadas contradictorias en su doctrina, media un lapso de tiempo no superior a veinte días), al tener que pronunciarse esta Sala sobre este punto concreto lo hace en el sentido de tener por bien indicado el recurso procedente, por estimar que no procede la reposición previa a la alzada, ya que, si bien es cierto que el recurso de reposición tiene por objeto someter a nuevo examen del propio órgano administrativo que dictó el acto toda la cuestión decidida, por si estimara procedente volver sobre lo acordado inicialmente, este objeto del recurso cede cuando se concede otro ante un órgano jerárquicamente superior al que dictó el acto que se quiere impugnar. (Sentencia de 20 de diciembre de 1974, Ar. 5.220).

\section{RECURSO DE REPOSICIÓN: PLAZO}

Considerando: Que si bien el acto impugnado fue por primera vez notificado en forma defectuosa al no expresar los recursos contra él procedentes, ni la autoridad ante la que debían interponerse el 6 de octubre de 1971, a requerimientos del accionante la notificación se repitió, con cuantos requisitos exigen los artículos 404 de la Ley de Régimen local y 79 de la de Procedimiento administrativo, concordantes con el 311 del Reglamento de 17 de mayo de 1952, deduciéndose entonces el recurso de reposición, que se presentó el 30 de noviembre de 1971, siendo así que la notificación rectificada había sido practicada por la vía postal que autorizan el artículo 80 de la Ley citada de Procedimiento administrativo (desarrollada por la Orden de 22 de octubre de 1958) y el 313 del citado Reglamento de 17 de mayo de 1952, el día 28 de octubre del expresado año de 1971; o sea, que entre el recibo de la notificación y la presentación del recurso había transcurrido con exceso el plazo de un mes que señala el artículo 52 de la Ley Jurisdiccional, aplicable lo mismo a los procedimientos iniciados ante las autoridades locales o periféricas que ante las de la Administración central, por remisión expresa de los correspondientes preceptos administrativos al corpus iuris de la Ley de 27 de diciembre de 1956, no alterada en este punto por la reforma de 17 de marzo de 1973. (Sentencia de 11 de diciembre de 1974, Ar. 4.929). 


\section{RESPONSABILIDAD DE LA ADMINISTRACION}

\section{ARTículo 40 DE LA LEY dE RÉGimen JURÍdico dE LA AdMinistración DEL ESTADO}

10. Que la responsabilidad patrimonial de la Administración pública, ya tenga su origen en el incumplimiento de contratos, ya en una actividad extracontractual, ya se deba esta última a malicia o culpa de sus órganos o funcionarios, o simplemente al mero funcionamiento -normal o anormal- de los servicios públicos, ha pasado en los últimos años por tres etapas legislativas muy características y siempre en un sentido progresivo y ampliatorio de los derechos de los administrados afectados, representada la primera por los artículos 405 y 406 de la Ley de Régimen local aplicables únicamente a las Entidades y Corporaciones locales, pero cuya regulación vino a ser sustituida por la fórmula más generosa contenida en el artículo 121 de la Ley de Expropiación forzosa, de aplicación a toda la Administración pública, incluso a la local o institucional, conforme a lo dispuesto en el artículo 133.2 del Reglamento de esta Ley, regulación que ha encontrado su plasmación definitiva en el artículo 40 de la Ley de Régimen jurídico de la Administración del Estado, a cuyo tenor "los particulares tendrán derecho a ser indemnizados por el Estado de toda lesión que sufran en cualquiera de sus bienes y derechos, salvo en los casos de fuerza mayor, siempre que aquella lesión sea consecuencia del funcionamiento normal o anormal de los servicios públicos...», regulación, en definitiva, acorde con los más elementales principios de justicia, en cuanto dispone que los daños causados a los particulares, por el funcionamiento de los servicios públicos que benefician a toda la colectividad, no sean soportados individualmente por los afectados sino por la generalidad de los ciudadanos a través de la propia Administración. (Sentencia de 11 de diciembre de 1974, Ar. 5.132):

\section{SEGURIDAD SOCIAL}

\section{Ayuntamientos: cuota EmPRESARIAL EN LA SEguRIDAd Social AGRARIA}

Considerando: Que de acuerdo con el criterio establecido en numerosísimas sentencias de esta Sala, siguiendo el asimismo proclamado por el Tribunal Supremo en sentencia de 9 de junio de 1970 y, sobre todo, en la de 23 de marzo de 1971, cuota empresarial del Régimen de la Seguridad Social Agraria, y por tratarse de un seguro obligatorio, por razones y finalidades de orden social, en el que es preciso que se dé el binomio empresario-trabajador, sólo puede ser exigida a quienes ostenten la condición de empresarios, condición que no concurre en la 
Entidad local recurrente, ya que según certificaciones aportadas en período probatorio, aquella Corporación no tiene personal afecto a la explotación de los montes de su propiedad inscritos en el Catálogo de Utilidad Pública, por lo que no tiene constituida empresa agraria, puesto que el personal que allí trabaja, lo hace por cuenta de ICONA o de los adjudicatarios de los aprovechamientos de maderas, y ante la realidad de estos hechos, debe estimarse el recurso. (Sentencia de 24 de enero de 1975, Ar. 133).

\section{OTRA SOBRE EL MISMO TEMA}

Considerando: Que de acuerdo con el criterio establecido en numerosísimás sentencias de esta Sala, siguiendo el asimismo proclamado por el Tribunal Supremo en sentencias de 9 de junio de 1970 y, sobre todo, en la de 23 de marzo de 1971, la cuota empresarial del Régimen de la Seguridad Social Agraria, y por tratarse de un seguro obligatorio, por razones y finalidades de orden social, en el que es preciso que se dé el binomio empresario-trabajador, sólo puede ser exigida a quienes ostenten la condición de empresarios, condición que no concurre en la Entidad local recurrente, ya que según certificaciones aportadas en el período probatorio de estas actuaciones, aquella Corporación no tiene personal afecto a la explotación de los montes de su propiedad inscritos en el Catálogo de Utilidad Pública ni tiene constituida empresa agraria para dicha explotación, adjudicándose en subasta pública los aprovechamientos de los montes mencionados, por lo cual y ante la realidad de estos hechos debe estimarse el presente recurso. (Sentencia de 10 de febrero de 1975, Ar. 464).

\section{OTRA SOBRE LA MISMA CUESTIÓN}

Considerando: Que la fijación de cuota, objeto de este pleito, corresponde al ejercicio de 1967, en que era plenamente aplicable en su redacción primitiva la Ley de Seguridad Social de 31 de mayo de 1966; por lo que, al no ser posible tener en cuenta ahora, por falta de retroactividad expresa, las disposiciones legales y reglamentarias posteriores a la citada Ley, las que han tenido total vigencia a los efectos que aquí pudieran interesar, después del ejercicio de 1971, es indudable que en el caso presente, y sin adelantar en absoluto futuras soluciones, hay que mantener las dos premisas fundamentales que sirven de supuesto al fallo apelado y que son: carácter económico-administrativo inicial de la cuestión surgida con motivo de la fijación de cuota antes referida por la asimilación que el artículo 46 de la Ley de.31 de mayo de 1966 hace a la contribución rústica y pecuaria; y exigencia del binomio «empresario-trabajador" para el sometimiento al pago de la cuota empresarial que se configura en 1966 como auténtico seguro obligatorio; todo 
lo cual conduce a confirmar íntegramente la sentencia objeto del presente recurso de apelación; sin que sea de apreciar temeridad ni mala fe al efecto de una especial imposición de costas. (Sentencia de 14 de febrero de 1975. Ar. 780).

\section{SERVICIOS}

\section{MERCADOS: SUBIDA DE TARIFAS: AUDIENCIA DE LOS INTERESADOS}

ConsIDERANDo: Que la Administración municipal demandada incurre, al sostener la tesis de que se ha hecho mención, en notorio error al interpretar en el sentido que lo hace, el artículo 151 del Reglamento de Servicios. Este precepto, en sus números 1 y 2 , no es otra cosa que la formulación del poder de la Administración para controlar las tarifas de utilización del servicio, facultad de poder que reconocemos puede ejercitar no sólo unilateralmente, sino también sin intervención alguna de los usuarios, pero solamente cuando se trata de servicios públicós uti universi o prestaciones administrativas realizadas en contemplación de la colectividad general, pero no si, como en el caso presente, el servicio o prestación es uti singuli que, por originar relaciones directas y paccionadas entre la Administración y ciertos administrados en concreto, la modificación de dichas tarifas entraña una alteración de las cláusulas contractuales que las establecieron, y por ello motivan que no pueden autorizarse sin intervención o audiencia, en primer lugar, del concesionario. Esta natural y lógica exigencia del artículo 151 que comentamos no significa que si la relación jurídica reguladora de la prestación del servicio está constituida no ya bilateralmente entre el concesionario y la Administración, sino que en ella interviene una tercera parte, no deba extenderse a ella la misma audiencia, pues en estos casos, junto al concesionario actúan aquellos usuarios también uti singuli, ligados todos en una trama de relaciones jurídicas cuyo último eslabón son, en este caso, los usuarios de los locales en alquiler, con una relación inmediata del concesionario que actúa con poderes delegados de la Administración, la cual conserva sus potestades indeclinables para controlar unas tarifas que en principio van a ceder solamente en beneficio del concesionario y a cargo de aquellos usuarios concretos y determinados. El hecho de que el núm. 2. del artículo 151 que examinamos no se refiere más que a la relación bilateral administrador-concesionario, no es obstáculo para que aquellos usuarios arrendatarios del servicio en quienes con carácter singular y en virtud de una relación particular de derecho, va a recaer en definitiva la obligación del pago no hayan de ser considerados como «interesados» a los efectos del artículo 296 del Reglamento de Organización que, por tratarse de personas perfectamente determinadas y conocidas por la Administración, debieron ser requeridas por escrito para que se personasen si así les convenía en el expediente, como manda el 
número 2.० del expresado artículo 296. Incumplido por el Ayuntamiento de Madrid este mandato, cuya trascendencia de indefensión por evidente y notoria no es necesario razonar, resulta evidente y notoria también la nulidad del expediente municipal y de las resoluciones recurridas a que éste dio lugar por virtud de lo dispuesto en el núm. $2 .^{\circ}$ del artículo 48 de la Ley de Procedimiento administratvo. (Sentencia de 12 de diciembre de 1974, Ar. 4.930).

\section{TELÉfonos: CABINA EN VÍA PÚblica mUNICIPAL}

Considerando: Que por el carácter de bienes de dominio público que corresponde a las vías urbanas conforme al artículo 324 del Código Civil y 183 y 184 de la vigente Ley de Régimen local de 24 de junio de 1955, cuyo último precepto define como bienes de uso público municipal, de conformidad con el párrafo $1 .^{\circ}$ del artículo 334 del Código Civil, entre otros, los caminos, plazas, calles y paseos de servicio general cuya conservación y policía sean de competencia del Municipio, lo que en modo alguno se pone en duda en el presente caso respecto a la calle en que se ha de emplazar la cabina telefónica, es indudable la competencia del Ayuntamiento de Zaragoza respecto a la adopción de los acuerdos que con sujeción a las normas aplicables para los acuerdos municipales puedan resultar procedentes para el cumplimiento de sus fines de carácter urbanístico, de tráfico y generales, por lo que está ajustada al ordenamiento jurídico la cláusula o condición enunciada en la autorización municipal bajo la letra e), debiendo conservarse como válida, sin que, en cambio, deba prevalecer la otra cláusula litigiosa enunciada bajo la letra $f$ ) en cuanto atribuye a la Alcaldía una facultad de simple revocación de la autorización que se conceda, revocación que sólo por los cauces legales pertinentes podría acordarse. (Sentencia de.16 de enero de 1975, Ar. 38).

\section{URBANISMO}

\section{Planes de ordenación: aPRobación CONDICIONADA}

Los poderes otorgados al órgano urbanístico alcanzan tanto a calificar la legalidad como la oportunidad o conveniencia y la corrección técnica del plan sin limitación alguna, lo cual no cabe dentro de una simple actividad de fiscalización o control y sí como un acto final que confiere valor legal al plan y donde se ejercita una competencia compartida en la cual los actos de formulación son meramente preparatorios, y el de aprobación definitiva corresponde con plenitud de atribuciones, en cuanto a la legalidad y oportunidad, al órgano urbanístico, tal como ya se desprende de la sentencia de esta Sala de 29 de octubre de 1967, citada por el mismo recurrente; claro que así configuradas esas po- 
testades, al dictarse el acto de aprobación definitiva podrá tanto aprobarse o reprobarse el plan íntegramente y para nuevo trámite (en los casos en que sea precisa nueva formulación) como aprobarlo parcialmente $\mathrm{y}$ no para un sector determinado, tal como evidencia el artículo 44, o intreducir modificaciones incluso mediante una aprobación condicionada a su documentación o incorporación, limitando el efecto de la nueva elevación a la homologación de la ejecución del mandato, sobre todo cuando las referidas modificaciones sean tan concretas que baste, como en este caso, la simple alteración numérica de un precepto (como las alturas de la zona intensiva) o la supresión de otros (en las normas complementarias) de tal suerte que la referida homologación posterior supla un nuevo trámite aprobatorio totalmente innecesario; aprobación condicionada cuya legitimidad ya se admitió por la sentencia de esta Sala de 4 de junio de 1970, que estimó legítimo el condicionamiento de la aprobación del plan a la subsanación de deficiencias, como también la exoneración de un nuevo trámite de información pública, en cuanto señala que «es del todo correcto que sin necesidad de nueva información pública pudiera llegarse a la aprobación del plan... por simple elevación del mismo a la Comisión Provincial de Urbanismo... una vez que en él fueron subsanadas las deficiencias anteriormente apreciadas". (Sentencia de 2 de diciembre de 1974, Ar. 5.020).

\section{VIVIENDAS}

\section{Facultades de las antiguas Fiscalías de la Vivienda,} hoy Delegaciones Provinciales de la Vivienda

Considerando: Que el Delegado provincial de la Vivienda - al igual que la Dirección General al resolver la alzada - es autoridad competente para imponer obras de reparación, etc., en finca urbana habitada, tal como prescriben el apartado $20^{\circ}$ del artículo $50^{\circ}$ en relación con el $10^{\circ}$ del Decreto de 23 de noviembre de 1940, en conexión con la norma contenida en el apartado $b$ ) del artículo 12 del Decreto de 3 de octubre de 1957, ya que les están encomendadas las facultades precisas para velar por las condiciones de salubridad e higiene de la vivienda humana, inspeccionando y adoptando las medidas adecuadas al efecto (artículos $1 .^{\circ}, 4 .^{\circ}$ y $50^{\circ}$ y concordantes del Decreto de 23 de noviembre de 1940), cualquiera que sea la situación jurídica de la finca, ya que mientras la misma continúe habitada, el propietario vendrá obligado a adoptar las medidas que la autoridad ordene, y entre ellas las referentes a la salubridad e higiene del edificio, que puede imponer, desde luego, la autoridad de Vivienda, en cualquier momento y mientras el edificio no se destruya o demuela.

Pero al ordenar puramente la reparación de cubierta y fachada, las traslada sin más al campo de las medidas de seguridad, por cuanto que el único informe técnico existente en el expediente afirma el mal estado 
de conservación del edificio surgido del desplome o desprendimiento de un muro que exige necesariamente la adopción de medidas u obras de reparación o más propiamente de consolidación del muro que indudablemente exceden de los cometidos o atribuciones que a las autoridades de Vivienda - por asunción de las facultades atribuidas inicialmente a las Fiscalías - otorgan los preceptos reglamentarios citados, pues si bien las autoridades municipales aparecen investidas de facultades amplias y de rango legal que legitiman su actuación en el campo de la policía de edificios y de la construcción por cualquier causa (seguridad, salubridad, higiene, etc.), la atribución a las por nosotros llamada autoridad de Vivienda se limita a los casos de salubridad e higiene de vivienda humana, pudiendo imponer la realización de reparaciones y obras adecuadas a tales fines, si bien en todo caso tales decisiones deben ser motivadas y suponer, a su vez, una orden concreta de realización de obra determinada y proporcionada al fin propuesto, puesto que si así no acontece nos encontramos ante un supuesto de extralimitación objetiva, como aquí ocurre, al ordenar la realización de unas obras de reparación - incluso técnicamente podrían ser de reconstrucción de un muro reventado- que exceden notoriamente de su ámbito atribucional. (Sentencia de 31 de diciembre de 1974, Ar. 5.224).

Nemesio RodrfGuez MORO 
REVL-1975, núm. 188. SANCHEZ ISAC, JAIME. LA DUALIDAD DE JURISDICCIONES EN LA CA... ` REVL-1975, núm. 188. SANCHEZ ISAC, JAIME. LA DUALIDAD DE JURISDICCIONES EN LA CA... 